\title{
The sister concepts of the working alliance and the real relationship: on their development, rupture, and repair
}

\author{
Charles J. Gelso, ${ }^{1}$ Kathryn V. Kline ${ }^{2}$ \\ ${ }^{1}$ Department of Psychology, University of Maryland, College Park; ${ }^{2}$ Department of Counseling, Higher Education, and Special Education, \\ University of Maryland, College Park, MD, USA
}

\begin{abstract}
Jeremy Safran has presented seminal and widely applicable clinical theory and research around the therapeutic alliance and ruptures in the alliance. We explore areas of agreement with and departure from some of Safran's key conceptualizations on these topics, focusing on overlap and distinctions between two constructs theorized to be fundamentally significant elements of all therapeutic relationships: the working alliance and the real relationship. We share Safran's view that the alliance centrally implicates an emotional bond between patient and therapist, as well as an agreement about the goals of treatment and the tasks needed to attain those goals. We depart from Safran, however, in his belief that the real relationship should be seen as part of the emotional bond of the working alliance. Instead, we argue that the real relationship and the working alliance (including the bond aspect of the alliance) are best viewed as highly interrelated but distinct aspects of the therapeutic relationship. In addition, a distinction is made between the working bond (part of the working alliance) and the personal bond (part of the real relationship). Hence, we examine the concept of rupture in the working alliance, and in the real relationship as well. The nature of ruptures is discussed, as well as what therapists can do to repair them. A more limited definition of ruptures than the broader conception that has evolved in recent years is proposed. It is suggested that, whereas ruptures in the working alliance generally can be repaired to the benefit of the work, ruptures in the real relationship are likely to be more damaging to the treatment.
\end{abstract}

Key words: Therapeutic alliance; Real relationship; Rupture-repair.

\section{Introduction}

Jeremy Safran was one of the most important psychotherapy scholars of his generation. His contributions

Correspondence: Charles J. Gelso, Department of Psychology, University of Maryland, College Park, MD, United States.

E-mail: gelso@umd.edu

Citation: Gelso, C. J., \& Kline, K. V. (2019). The sister concepts of the working alliance and the real relationship: on their development, rupture, and repair. Research in Psychotherapy: Psychopathology, Process and Outcome, 22(2), 142-149. doi: 10.4081/ripppo.2019.373

Conflict of interest: the authors declare no potential conflict of interest.

Funding: none.

Received for publication: 17 January 2019.

Revision received: 12 March 2019

Accepted for publication: 1 April 2019.

This work is licensed under a Creative Commons Attribution NonCommercial 4.0 License (CC BY-NC 4.0).

${ }^{\circ}$ Copyright: the Author(s), 2019

Licensee PAGEPress, Italy

Research in Psychotherapy:

Psychopathology, Process and Outcome 2019; 22:142-149

doi:10.4081/ripppo.2019.373 were far reaching, encompassing several key areas within psychotherapy theory and research. As anyone who worked with Jeremy or read his work could readily see, Jeremy was a highly creative and fertile thinker, and as a big part of his creative energy, Jeremy loved to discuss and debate ideas. The first author participated in many meetings with him and often agreed with his frequently provocative and always thoughtful views, but at times we naturally disagreed. In the spirit of debate that Jeremy loved and was energized by, in this tribute we shall explore ideas that depart from Jeremy's, as well as those that are in agreement. Two of Jeremy's greatest contributions, in our view, focused on the therapeutic alliance and its development, and on ruptures in the alliance. In the present paper, we discuss each of these and examine areas of agreement and divergence. We focus on the connection of Safran's conceptions of the alliance and the rupture-repair process to what we see as an overlapping but distinct construct, what has been referred to as the real relationship in psychotherapy (e.g., Gelso, 2011, 2019). Three primary points are addressed: i) the value of separating the working alliance from the real relationship; ii) the need to narrow the conception of ruptures; and iii) the potentially differing impact of ruptures in the working alliance and ruptures in the real relationship.

It should be noted that virtually all of Safran's most profound work on the therapeutic alliance was done in collaboration with Christopher Muran. These two formed an enormously effective team over many years, and their contributions will surely pass the test of time. Nearly all 
of our references to Safran's work below incorporate his collaboration with Muran.

\section{The working alliance and the real relationship}

Two of the most basic elements of all therapeutic relationships may be termed the working or therapeutic alliance and the real relationship. For Safran and Muran (e.g., Eubanks, Muran, \& Safran, 2018a; Eubanks, Muran, \& Safran, 2018b; Safran \& Muran, 2000), the two elements merge in the sense that the real relationship is seen as a part of the therapeutic alliance. Drawing on the seminal work of Bordin (1979), the therapeutic alliance is viewed as being composed of an emotional bond between therapist and patient, and an agreement on the goals of treatment, as well as the tasks that will be effective in attaining those goals. The more positive the emotional bond, and the greater the agreement on goals and tasks, the stronger will be the therapeutic alliance. The emotional bond element of the alliance is conceptualized largely as a real relationship in the sense that it is the nontransferential person-to-person connection between patient and therapist.

We certainly share Safran's view of the importance of the therapeutic alliance, as well as his many elaborations of how and why the alliance works (Safran \& Muran, 1998, 2000). However, our view is that it is theoretically and clinically useful to separate the working alliance and the real relationship. To be sure, the two are inarguably highly interrelated, to the point that they may be seen as sister concepts (Gelso, 2014). Still, they are also distinct in their contribution to treatment process and outcome, as has been demonstrated in several studies (Bhatia \& Gelso, 2018; Gelso, 2014). We are inclined to divide the emotional bond between therapist and patient into two sub-elements: a working bond and a person-to-person bond. The former is part of the working alliance, and includes the connection that comes from the therapist and patient doing their jobs well, the patient trusting that the therapist can be counted on to conduct the treatment wisely and effectively, the therapist's motivation to do the work of therapy, and the patient's sense that the therapist understands him or her. As can be seen, the key feature of this working bond is that it pertains to the work connection between therapist and patient. In contrast, the personal or personto-person bond that constitutes the real relationship is not directly related to the work of therapy, but instead is a function of two human beings coming together, where each appreciates the person of the other, and in its most positive rendering, each enjoys and likes the other.

The real relationship, following Greenson's (1967) early lead, is seen as consisting of two elements, realism and genuineness. As conceptualized by the first author (Gelso, 2009, 2011), realism includes the realistic perceptions and experiences of the other person, uncontaminated by transference. It involves perceiving/experiencing the other as they truly are, rather than as projections based on the unresolved issues of the perceiver. Genuineness, on the other hand, involves the participants relating to each other in a way that is non-phony and authentic, even as each plays out the roles they must take (i.e., patient role and therapist role). The more positively are the therapist and patient's realistic and genuine feelings for one another, the stronger the real relationship. The first author has elsewhere (Gelso, 2011, Chapters 3 and 6) discussed in detail philosophical, theoretical, and measurement considerations regarding the real relationship, e.g., how do we know what is realistic and what is transferential, who decides what is real and genuine, how is the real relationship best measured.

We see it as important and useful for the two kinds of bonds (the personal bond and the working bond) to be differentiated, although both types of bond are emotional in that they are bonds of feeling/affect (as well as thinking/cognition). Parenthetically, it would be reasonable to subsume the two kinds of bonds separately within the working alliance construct. However, we believe it is theoretically cleaner and more clinically practical to theorize the working alliance and the real relationship as separate but highly related constructs.

The psychoanalyst, Greenson (1967), theorized that the working alliance emerges from the real relationship. A real relationship exists in all relationships, whereas Greenson saw the working alliance as being an artifact of treatment, one that exists for the sole purpose of fostering the work of analysis. In our researches on the topic, we have arrived at a different conclusion, that is, the real relationship and working alliance emerge simultaneously and work in concert, with each feeding the other. The patient is inclined to be motivated to do the work of therapy when s/he personally resonates to the therapist, and working well together creates a sense of personal connection and liking.

The working alliance and the real relationship also work in concert in another way (see the qualitative study by Gelso, Hill, Mohr, Rochlen, \& Zack, 1999). They serve as buffers against the potentially damaging effects of the patient's transference reactions, especially those that endanger the treatment, usually referred to as negative transferences.

We have explored how the working alliance and the real relationship are best seen as related but separate constructs, and how the bond element of the working alliance (termed the working bond) may differ from the personal or real relationship bond. At the level of measurement, an ongoing problem has been that the Working Alliance Inventory, the main measure of working alliance, contains a bond subscale that conflates the work part of the bond and the personal bond. We believe that it would be useful to separate these in the measure itself, perhaps eliminating the personal bond items from the measure. Alternatively, it could be useful to create a four-factor model of the general alliance or therapeutic relationship consisting of a real relationship (involving a personal bond), a work bond, 
agreement on goals, and agreement on tasks needed to attain those goals. A measure may be developed to capture these elements. It would not, however, be called a working alliance scale, but rather a general alliance or relationship scale. The key point in both these conceptualizations is that the real or personal relationship would be conceptualized and measured separately from the working bond, agreement on goals, and agreement on tasks.

\section{When the working alliance and the real relationship are not in synchrony}

Given the difficulty and complexity of psychotherapy, it is natural and expected that therapists will at times struggle to connect with their patients. Sometimes this difficulty is related to not knowing how to help the patient or mistaking what will be therapeutic. Thus, the working bond will suffer. At other times, this difficultly is related to a weak personal connection, or a lack of appreciation for the person of the other, resulting in a weak personal bond. As the therapy unfolds, therapist and patient start to connect on what to do in therapy to help the patient move forward and a working bond ensues, which can vary in strength throughout the treatment. In addition, there is virtually always at least a degree of taking to, caring for, and connecting to the patient that is based upon who the patient and therapist are as persons and not based on the work. At times, we can even speak of love in psychotherapy that is not merely transference love, but residing in the area of the real relationship (Gelso, 2019; Gelso, Pérez-Rojas, \& Marmarosh, 2014). In its best rendition, this person-to-person connection happens from the first moment of contact and builds or solidifies steadily. However, few if any therapists feel strongly connected to all of their patients as persons. At times, the real relationship is weak early in treatment, while the working alliance (including the working bond) may be solid. In addition, in some cases, the real relationship may never become strong, but the work can be successful because the working alliance (including the working bond) is sufficiently strong. Still, we believe that the work will likely not be as successful as it would have been had both the alliance and the real relationship been strong. A case example of a patient worked with by the second author (KVK) demonstrates such a situation.

Annie and I worked together for a year and a half in individual psychodynamic psychotherapy. Annie, a 40-year-old woman, sought treatment because she had hit rock bottom. She was recently dismissed from her graduate school program due to failure to pass comprehensive exams, living with her brother because she was unemployed, and had zero confidants. Hence, she was extremely depressed and carried significant anxiety about her next steps in life, resulting in frequent panic attacks and crushing inertia.

From our very first point of contact, it was evident that Annie and I were very different human beings. She, a reserved and introverted aspiring geologist, and I, an outgoing and extroverted aspiring psychologist, were clearly from different tribes. She was fascinated by rocks, whereas I was fascinated by people. It was also evident that we were aware of these differences - the looks at one another's drastically different clothing, the jokes made by both of us quickly followed by 'that probably wasn't funny to you,' and the pop culture references mentioned that we had to explain to one another. These person-to-person differences at times inhibited my feeling that I could be my genuine self with Annie, and I felt that she infrequently saw the 'real' me. This was likely because I did not feel who I was would be appreciated and therefore did not readily expose my personality as much as I did with other patients. I rarely enjoyed being with Annie or experienced any excitement to see her. While a transferencecountertransference configuration was surely a significant part of our dynamic, the disconnect between us was more than distortion on her end and activation of unresolved conflicts on mine. Overall, our real relationship, or personal emotional bond, was not strong. It was difficult to resonate with one another, which prevented us from deeply connecting as persons. We were from different worlds in fundamental ways (e.g., things we valued, sense of humor, likes and dislikes, personality traits), and it would be difficult for this person-to-person connection to grow significantly short of our becoming different people.

One might guess that the lack of personal connection just described would result in an unsuccessful or perhaps even damaging therapy, but this was not the case. Despite the lack of an emotional person-to-person bond, we felt a different type of emotional bond that originated from our work in therapy. I was empathically in tune with how to help Annie crawl out of her paralyzed and panicked state. Annie knew and communicated that I understood helpful ways to work with her. For example, she appreciated my pushing her to do the work, but at the right intensity and times. Hence, Annie felt an emotional connection to me because she trusted that I could help her do the painful work of therapy in a more palatable way. I also felt an emotional connection to Annie based on what she was going through in life. I cared for her and wanted her to not be so depressed and anxious. We formed an emotional bond that developed and strengthened in the therapy room, but that would be nonexistent outside of it. Overall, our connection was rooted in the work we were doing and this was integral to Annie's improvement. At the end of treatment, Annie no longer suffered panic attacks, 
began a volunteer job that would likely lead to a paid position, and reconnected with several friends.

This case begs the question of why the person-toperson bond matters if the working bond was strong enough to foster a successful outcome. The truth is, although we accomplished a great deal in our work, we were likely limited for a couple reasons. First, given that I did not particularly connect with Annie as a person, I struggled to empathize with her more often than with other patients. In addition, other patients with whom I easily connected on a personal level likely received more of my motivation to do good work. This highlights how the real relationship can influence the working alliance. On Annie's end, I speculate that our weak personal bond made her question if I could be of any help to her, especially early in treatment. It is possible that she too felt less motivated to do the work of therapy at times because of our weak personal connection. Second, we seemed held back in being our genuine selves due to the accurate interpretation that the other would not fully 'get it,' and this cut off the possibility for Annie to heal through the genuine and realistic aspects of the therapeutic relationship. Hence, I believe our work could have reached greater heights if we had a stronger connection at a person-to-person level.

What happens when the person-to-person bond is strong but the working alliance is weak? It is hard for us to imagine the treatment being successful in the absence of a sound working alliance, and a strong working bond that is part of that alliance. Preliminary research suggests that discrepancy between the working alliance and real relationship is related to different outcomes, depending on the client and time point of therapy. Kivlighan, Kline, Gelso, and Hill (2017) found that some clients rated higher session quality when the real relationship was stronger than the working alliance, whereas other clients rated higher session quality for the reverse. In addition, higher client-rated session quality was associated with a stronger real relationship than working alliance during some sessions, while the reverse was true for other sessions. Hence, according to clients, a strong working alliance is at times more helpful than a strong real relationship, and vice versa. Further, it seems that different clients find different relationship qualities more or less helpful. Thus, it is important to examine moderators, such as client attachment and symptomatology, to clarify client characteristics and points of therapy related to the degree of importance for the working alliance $v s$ real relationship. Lastly, it is also important to note that Kivlighan et al. (2017) also found that the highest session outcome was related to both working alliance and real relationship being strong, which supports clinical theory that the best treatment would encompass a strong working alliance and real relationship. While it is tempting to offer propositions on which relationship component (i.e., working alliance or real relationship) is more important for treatment, initial evidence suggests that this is determined by client factors, time point in therapy, and likely additional factors. Hence, we believe that it is more helpful to examine the experience and impact of the working alliance and real relationship not being in synchrony, as described in the case above.

\section{Tear and repair: when ruptures occur in the therapeutic relationship}

The concept of tear and repair in the working alliance originated with the work of Bordin (e.g., Bordin, 1979, 1994). Safran and Muran refined Bordin's conceptions and further developed ideas around ruptures and how the therapist may repair them. We believe that in his work around rupture and repair in the therapeutic alliance, Safran has arguably made his most profound and farreaching contributions. Below we discuss what we see as Safran's most significant conceptions. We also point to a difficulty in the rupture literature that is itself in need of repair, that is, the undue broadening of the construct of alliance rupture.

In Safran and colleagues' most recent article on rupture repair, a rupture is defined as a deterioration in the therapeutic alliance manifested by a disagreement between patient and therapist on the goals, a lack of collaboration on tasks, or a strain in the emotional bond (Eubanks, Muran, \& Safran, 2018a, p. 2). While this definition sounds sufficient, the point at which we diverge from Safran is regarding the intensity, or strength, of the deterioration. Many examples provided in Safran's work (e.g., Safran \& Muran, 2000) suggest minor or even benign conflicts as ruptures. Furthermore, many empirical examinations of alliance ruptures consider subtle tensions and minor strains as ruptures (Eubanks et al., 2018a).

The problem manifests especially in the distinction between surface level repairing strategies and strategies that speak to the underlying meaning of the conflict. Safran and Muran (2000) discuss how ruptures may require a therapist to intervene at the surface level or at the level of underlying meaning. For example, if a patient questions the therapist about why they are doing free association, this could signal a conflict about the therapy tasks. Therapists can respond at the surface level by providing a rationale for free association, or they can respond to the underlying meaning by exploring what core theme this task recapitulates for the patient (e.g., the patient's fear of exposing himself too quickly, thereby losing control in relationships). Important clinical information such as the length of therapy, the strength of the therapeutic relationship, and the way in which the patient raised this conflict 
would matter in determining whether the therapist should intervene at the surface or underlying meaning level. In our view, any conflict between patient and therapist in which a surface-level repair suffices is not likely to be a rupture at all. Hence, these surface-level interventions could be seen as tending to the alliance, but not repairing a part of the alliance that has been broken. In a similar vein, Safran and Muran (2000) categorize repairing strategies as immediate or expressive. Immediate strategies focus on repairing the rupture expeditiously and returning to the therapy process the therapist and patient were engaged in prior to the rupture. In contrast, expressive strategies shift the focus of the therapy session to address the patient's concerns that underlie the rupture. We would argue that a conflict that could be repaired expeditiously is not a rupture, but rather a minor conflict, and at times so minimal as to not even represent a conflict. In sum, we believe this highlights an important distinction, that is, the term rupture ought to be reserved for conflicts that require the therapist to intervene in a deeper and more time-intensive manner.

When determining the strength of a conflict in the therapeutic relationship and whether to respond at an expeditious, surface-level or time-intensive underlying meaning-level, the point of perspective is raised. That is, who determines - therapist or patient - the degree of severity of the conflict? It is possible that clients withhold feelings about the issue and thus a surface-level repair may not actually suffice. Hence, the argument can be made that it is better to be safe than sorry and for therapists to be attuned to any fluctuations in the relationship. We fully believe it is important for therapists to be attuned to all strains in the therapeutic relationship. However, what is the ultimate utility of calling every strain a rupture? Do we think that if every strain is given this title, therapists will be more attuned or more likely to address and intervene? Perhaps this is the case, but alternatively, it is important to examine what problems could arise by using the term rupture too loosely. We address these potential problems at the end of this section.

Although it can be difficult, if not impossible, to be certain about what alliance conflicts are major $v s$ minor, we suggest there are three factors that can aid in this distinction. First, as we have discussed, we believe it is important to consider the intensity of the conflict. If the conflict is not powerful and the therapist and patient can move on easily and quickly, then we would not label this a rupture. However, it is possible that minor tensions building over time that go unaddressed could lead to a major conflict, which we would then call a rupture. Second, the conflict's centrality to the patient's issues or goals is important to consider. A true deterioration in the alliance would mean that the conflict between therapist and patient is at the heart of the patient's issues and is essential to repair if the work is to progress in any meaningful way (Bordin, 1994). Third, it is important to consider the de- gree to which the conflict endangers the therapeutic relationship. A rupture, if unaddressed, would seriously jeopardize the alliance and therefore the therapeutic work. Empathic failures on part of the therapist, which we will address later in greater detail, speak to the type of conflict that we consider deserving of the rupture label.

The existing rupture measures run what we see as a risk of categorizing minor conflicts as ruptures. For example, the Post-Session Questionnaire (PSQ; Muran, Safran, Samstag, \& Winston, 1992) is a self-report measure given to therapists and patients that asks, Did you experience any tension or problem, any misunderstanding, conflict, or disagreement, in your relationship with your [therapist or patient] during the session? Raters are asked to score on a 5-point Likert Scale ranging from not at all to very much, followed by rating how tense or upset they felt about the conflict on a similar 5-point scale. In studies using this measure, we would argue the importance of reserving ruptures for reports of higher rated conflicts, but this guidance is not given in the measure. Hence, it is possible that any conflict may be counted as a rupture. The Rupture Resolution Rating System (3RS; Eubanks, Muran, \& Safran, 2015, Rupture Resolution Rating System (3RS): Manual. Unpublished manuscript) is the primary observer-rated rupture measure and states that it codes for minor tensions and strains as well as major disagreements (p. 5). Similar to the PSQ, the 3RS allows raters to rate the significance of the rupture on the alliance using a 5-point scale from no significance to high significance. Thus, conflicts of low significance are being labeled as ruptures. Perhaps our divergence from Safran and colleagues is best illustrated in the introduction of the $3 \mathrm{RS}$ manual, which says a rupture may not significantly obstruct therapeutic progress. We would contend that, if unaddressed, any conflict deemed worthy of the term rupture would indeed obstruct therapeutic progress.

Now that we have reviewed what we see as a problem in the rupture literature, it is important to consider why we believe it is important to reserve the term rupture for meaningful conflicts. The primary reason is for construct clarity. As the first author notes in his work on countertransference (Gelso \& Hayes, 2007), casting too wide of a net for a construct could result in forgetting what one was fishing for in the first place. That is, if everything is a rupture, then nothing is a rupture; the construct becomes diluted to the point that meaningful relationships are likely to be obscured. It may be argued that because the rupture literature is in its early stages, it is important that measures like the 3RS and PSQ capture all strains so that we can determine what are major $v s$ minor problems in the therapeutic relationship. Because we do not have much empirical evidence about what is major vs minor conflict, measures need to capture all conflicts in the alliance and link them to outcome. We see the utility of this research strategy. However, this highlights the different needs 
within research and theory. From the vantage point of clinical theory, having this broad conceptualization of rupture yields an all-encompassing definition that is imprecise, and likely includes substantial excess baggage. Hence, it may breed confusion for practice when we discuss ruptures in supervision, trainings, case conferences, etc. Further, even though the worlds of research and practice can have different needs, we are always striving to bridge the gap between these worlds. Thus, it seems unwise to continue referring to all strains as ruptures when there is variability in the strength of such strains, and that continuing to do so could widen the disconnect between research and practice. A second reason it is important to use the term rupture for meaningful conflicts is that their effect and repair will be different from minor problems. Hence, if researchers are using the above measures in ways that group all conflicts together, then we are missing out on important distinguishing information between these two categories. A third reason it is important to reserve the term rupture for meaningful conflicts concerns training. Trainees in particular need a clear definition of strains $v s$ ruptures as they are beginning to learn the differences between building, maintaining, and repairing the alliance. Clear definitions of alliance conflicts would help trainees, supervisors, and instructors to be on the same page when discussing how to tend to the range of issues that arise between therapist and patient. Finally, we do not believe it is a good argument to call all strains ruptures solely because we cannot yet state, based on empirical evidence, what is a major conflict. Clinical theory may wisely precede empirical verification.

One major contribution Safran has made in the rupture literature that we believe is important to preserve is his dissemination of the classification of two types of ruptures, withdrawal and confrontation, as originally developed by Harper (1994). Withdrawal ruptures are characterized by patients dealing with misunderstandings or tension in the therapy relationship by becoming less involved, shifting focus to an unrelated topic, or becoming overly submissive to the therapist. Hence, patients withdraw or recede into the background of therapy. Typically the resolution process involves the therapist picking up on this withdrawal, helping the patient explore and express their negative feelings, and ultimately fostering communication of patient's wishes and needs. Confrontation ruptures, on the other hand, are characterized by patients directly expressing anger or dissatisfaction to the therapist. This type of rupture is more explicit and consequently typically requires an immediate repair attempt from the therapist. Resolution processes for confrontational ruptures usually involve the therapist becoming empathically attuned with the patient in order to understand and help the patient express disappointment and hurt. It is evident that these two categories are tremendously helpful clinically in determining how to spot and repair different types of ruptures. The two types call for differing tactics on the part of the therapist and thus serve as a guide to how the therapist may productively proceed. Thus, we believe it is important to maintain these categories, but it is also important to consider the three factors - intensity, centrality to patient's issues, and degree to which relationship is endangered - in determining whether or not a conflict constitutes a rupture.

\section{Ruptures in the alliance and ruptures in the real relationship}

Although the working alliance and real relationship may be seen as sister concepts, we suggest that there is a fundamental difference in how the phenomena of ruptures and repairs relate to the two constructs. Ruptures in the working alliance, as has been discussed, may have positive effects on the overall therapeutic endeavor if the therapist is able to work with and repair the ruptures (Eubanks, Muran, \& Safran, 2018b). And it does appear that most alliance ruptures can indeed be worked with and repaired by emotionally attuned, competent therapists. As the first author (Gelso, 2019) has stated:

In sum, the therapist needs to be sensitive to the occurrence of ruptures, and s/he needs to sensitively explore what the rupture is about. Repairing the rupture may involve the therapist clarifying where s/he was coming from, apologizing, and exploring the patient's feelings around the rupture. When the time is right, it is also important to explore the relation of the rupture, as well as the patient's way of dealing with the rupture, to the patient's core issues. However, to the extent that the rupture is fundamentally the responsibility of the therapist, it is important that the therapist not simply place the root of the rupture on the patient and his/her conflicts (p. 66).

Although empirical evidence is lacking, clinical experience suggests that ruptures in the real relationship, however, are not so readily repaired. We believe they are more likely to damage the therapeutic relationship, and they are less likely than ruptures in the working alliance to be ultimately beneficial to the overall relationship and treatment. Some preliminary evidence from two studies reported in Gelso (2011) supports this view in that patients who do well in therapy were not found to experience ruptures in the real relationship, whereas those who did not have good outcomes exhibited either a declining real relationship across the treatment or a single dip in the strength of the real relationship during the latter part of treatment.

Why are ruptures in the real relationship more harmful, and ultimately less helpful, than are ruptures in the working alliance? Before answering this question, we shall offer a preliminary definition of a real relationship rupture. A real relationship rupture may be seen as a failure on the part of the therapist to appreciate or demonstrate caring or empathy for the person of the patient at particular times when caring and empathy are called for, 
such that the patient consequently experiences painful affects tied to the therapist's response. Because the real relationship is personal, ruptures in it are also personal. Stated simply, the patient takes them personally. These ruptures most often reflect the therapist's lack of caring for the patient and/or significant empathic failures in a person-to-person sense. Greenson, long ago, offered that...Technical errors may cause pain and suffering, but they are usually repairable; failure of humanness is much harder to remedy (Greenson, 1978, p. 377). In discussing the genuineness element of the real relationship in psychoanalytic treatments, Couch (1999) tells us that...The absence of these natural responses by the analyst, especially when called for by actual tragedies, losses, failures, successes, disappointments and other significant events in the patient's life, can be the cause of the most serious errors in an analysis - namely the professionalized creation of an inhuman analytic situation, divorced from real life (p. 151). In sum, therapeutic errors revealing a deficiency in empathy and caring in a person-to-person way will tend to cause damaging ruptures in the real relationship from which the therapeutic relationship may not recover. We suggest that such ruptures rarely benefit the work of therapy, and even when they are repaired, the process of repair will likely take much longer than repairs in the working alliance because the therapist must re-convey his or her humanness and care for the patient and regain the patient's sense of personal trust. Finally, it seems clear that ruptures in the personal or real relationship are likely to weaken the working alliance.

Examples of ruptures in the real relationship taken from clinical practice and supervision are: The therapist taking phone calls during sessions making the patient feel uncared for; the therapist responding neutrally and blandly to a patient's excitement about having her first novel accepted for publication, a personal goal of hers for several years; a psychoanalyst maintaining analytic neutrality when a patient's child dies of an illness; a patient carrying a feeling, buffered by several examples, that his therapist doesn't particularly like him.

Ruptures in the real relationship can be occur from the beginning of treatment or they may become manifest later in the work. Regarding immediate ruptures, the therapist and patient may simply not connect as persons from the outset, perhaps being too different from one another, or as Gelso and Silberberg (2017) have framed it, being from different tribes (see the case of Annie, described earlier). This will naturally limit the strength of the therapeutic relationship, as well as the overall efficacy of the treatment. Of course, the reader may raise the question of whether this lack of the formation of a strong real relationship from the outset should really be considered a rupture, in accord with our definition above of a real relationship rupture. In other words, can a rupture occur without the development of a relationship to start with? We shall leave this question to future discussion. Less arguable is the proposition that ruptures in the real relationship can occur at any point in treatment tied to the lack of caring or empathic responses of the therapist.

\section{Working with ruptures}

Safran and Muran's (2000) formulations focused on working with confrontation and withdrawal ruptures is, in our view, a major and enduring advance in clinical theory. Safran and Muran provide detailed examples of the process of ruptures and ways of working with both kinds of ruptures. Their work is rich with clinical examples and actual patient-therapist interchanges, and it ought to be required reading for all therapy trainees (Safran \& Muran, 2000, Chapter 5). Here we provide a brief enumeration of points about ruptures and their reparation drawn from Safran and Muran, as well as our own conceptions (Gelso, 2019).

- Ruptures in the working alliance may well be inevitable, whereas ruptures in the real relationship appear to be less frequent.

- Ruptures are sometimes obvious but are more commonly subtle and require sensitivity and empathic ability on the part of the therapist to detect.

- It is wise for the therapist to be on the lookout for ruptures in both the alliance and the real relationship.

- Ruptures are most often expressed in the form of the patient's withdrawal behaviors and/or confrontation and complaining related to aspects of the work and the therapist's behavior.

- It is imperative that the therapist address ruptures. Unaddressed ruptures in the alliance will likely hinder progress, and unaddressed ruptures in the real relationship will likely seriously damage or destroy the overall therapeutic work.

- When ruptures are caused by therapist mistakes or errors, including empathic failures, an apology is usually wise, and it is also usually productive to follow the apology with exploration.

- When ruptures in the working alliance or the real relationship are caused by the patient's resistance, including transference, apologies on the part of the therapist are unlikely to aid progress. Instead, a sensitive exploration of the patient's issues is called for.

\section{Conclusions}

Jeremy Safran's keen intellect and his creative brilliance in understanding the therapeutic relationship was sadly ended long before its natural time. The focus of our presentation has been on his efforts toward understanding the development of the working alliance and the rupture-repair process pertaining to the alliance. We 
have added our notion of the real relationship as highly related to but distinct from the working alliance, and discussed how ruptures in the alliance $v s$ the real relationship are likely to have different impacts on the work. Although the lens through which we view the therapeutic relationship differs from Jeremy's in certain ways, his genius has deeply influenced our understanding, as well as the understanding of the entire field of psychotherapy. The loss of this creative brilliance will surely be felt deeply, but the ideas endure.

\section{References}

Bhatia, A., \& Gelso, C. J. (2018). Therapists' perspective on the therapeutic relationship: Examining a tripartite model. Counseling Psychology Quarterly, 31(3), 271-293.

Bordin, E. (1979). The generalizability of the psychoanalytic concept of the working alliance. Psychotherapy: Theory, Research and Practice, 16, 252-260. doi: 10.1037/h0085885

Bordin, E. S. (1994). Theory and research on the therapeutic working alliance: New directions. In A. O. Horvath \& L. S. Greenberg (Eds.), The working alliance: Theory, research, and practice (pp. 13-37). New York, NY: John Wiley and Sons.

Couch, A. S. (1999). Therapeutic functions of the real relationship in psychoanalysis. The Psychoanalytic Study of the Child, 54, 131-168.

Eubanks, C. F., Muran, J. C., \& Safran, J. D. (2018a). Alliance rupture repair: A meta-analysis. Psychotherapy, 55(4), 508519. doi: $10.1037 /$ pst0000185

Eubanks, C. F., Muran, J. C., \& Safran, J. D. (2018b). Repairing alliance ruptures. In J. Norcross \& M. Lambert (Eds.), Psychotherapy relationships that work (3rd ed.). New York: Oxford University Press.

Gelso, C. J. (2009). The real relationship in a postmodern world: Theoretical and empirical explorations. Psychotherapy Research, 19, 253-264. doi: 10.1080/10503300802389242

Gelso, C. J. (2011). The real relationship in psychotherapy: The hidden foundation of change. Washington, D.C.: American Psychological Association.
Gelso, C. J. (2014). A tripartite model of the therapeutic relationship: Theory, research, and practice. Psychotherapy Research, 24(2), 117-131.

Gelso, C. J. (2019). The therapeutic relationship in psychotherapy practice: An integrative perspective. London: Routledge.

Gelso, C. J., \& Hayes, J. A. (2007). Countertransference and the inner world of the psychotherapist: Perils and possibilities. Mahwah, N.J.: Lawrence Erlbaum Associates.

Gelso, C. J., Hill, C. E., Mohr, J. J., Rochlen, A. B., \& Zack, J. (1999). Describing the face of transference: Psychodynamic therapists' recollections about transference in cases of successful long-term therapy. Journal of Counseling Psychology, 46(2), 257.

Gelso, C. J., Pérez Rojas, A. E., \& Marmarosh, C. (2014). Love and sexuality in the therapeutic relationship. Journal of Clinical Psychology, 70(2), 123-134.

Gelso, C. J., \& Silberberg, A. (2017). Strengthening the real relationship: What is a psychotherapist to do. Practice Innovations, 1, 154-163. doi: 10.1037/pri000024

Greenson, R. R. (1967). The technique and practice of psychoanalysis (Vol. 1). New York, NY: International Universities Press.

Greenson, R. R. (1978). Explorations in psychoanalysis. New York, NY: International Universities Press.

Harper, H. (1994). The resolution of client confrontation challenges in exploratory psychotherapy: developing the new paradigm in psychotherapy research. (Doctoral dissertation). Sheffield: University of Sheffield.

Kivlighan, D. M., Kline, K. V., Gelso, C. J., \& Hill, C. E. (2017). Congruence and discrepancy between working alliance and real relationship: Variance decomposition and response surface analyses. Journal of Counseling Psychology, 64(4), 394-409.

Muran, J. C., Safran, J. D., Samstag, L. W., \& Winston, A. (1992). Patient and therapist postsession questionnaires, Version 1992. New York: Beth Israel Medical Center, NY.

Safran, J. D., \& Muran, J. (1998). The therapeutic alliance in brief psychotherapy. Washington DC: American Psychological Association.

Safran, J. D., \& Muran, J. C. (2000). Negotiating the therapeutic alliance: A relational treatment guide. New York: Guilford Press. 